\title{
Low energy proton induced reactions for CANS applications
}

\author{
$V$. Soukeras ${ }^{1 *}, O \cdot \operatorname{Sgouros}^{1}, A$. Pakou $^{2,3}$ \\ ${ }^{1}$ INFN - Laboratori Nazionali del Sud, Catania, Italy \\ ${ }^{2}$ Department of Physics, University of Ioannina, Ioannina, Greece \\ ${ }^{3}$ Hellenic Institute of Nuclear Physics (HINP), Ioannina, Greece
}

\begin{abstract}
The significance of comprehensive studies in the field of low energy proton induced reactions for applications related to Compact Accelerator - driven Neutron Sources was underlined in our recent work (O. Sgouros et al., Eur. Phys. J. A 57, 125 (2021)). In the present short article, the scientific concept together with the relevant simulations are discussed.
\end{abstract}

\section{Introduction}

The low - energy Compact Accelerator - driven Neutron Sources (CANS) have a significant role in research and development in science, as well as in engineering and education [1-4]. Their applications pertain to several scientific fields with high economical interest. Among them one may mention the materials characterization, applications in environmental studies, medical applications and non - destructive techniques useful in cultural heritage and engineering. The economical competitiveness and easy operation of CANS make them a good solution for long experimental runs needed in nuclear astrophysics or nuclear data campaigns [1]. Nowadays several CANS are currently operating or under construction worldwide from high to very low energies [3-11].

Two of the most widespread reactions for high neutron rate production at low - energies are the ${ }^{7} \mathrm{Li}(\mathrm{p}, \mathrm{n}){ }^{7} \mathrm{Be}$ and ${ }^{9} \mathrm{Be}(\mathrm{p}, \mathrm{n}){ }^{9} \mathrm{~B}$ reactions due to their large cross section. Therefore, a broad knowledge of the $\mathrm{p}+$ ${ }^{7} \mathrm{Li}$ and $\mathrm{p}+{ }^{9} \mathrm{Be}$ reactions is essential for low - energy CANS projects using a proton beam as underlined in Ref. [12].

Recent global experimental and theoretical studies in the Continuum Discretized Coupled Channels (CDCC) approach, for $\mathrm{p}+{ }^{6,7} \mathrm{Li}$ and $\mathrm{p}+{ }^{9} \mathrm{Be}$ [13-23], provide an important input to this direction. They also underline the role of the fundamental research in the field of applications. The reactions of interest for the visualization of CANS are presented in Table 1. The relevant neutron rate for a $1 \mu \mathrm{g} / \mathrm{cm}^{2}$ target was calculated in Ref. [12]. In the same work, the neutron rates for the proton energies of 3 and $5 \mathrm{MeV}$ were provided for a thick ${ }^{7} \mathrm{Li}$ or ${ }^{9} \mathrm{Be}$ target. Following the same methodology, the energy dependence of the neutron rates for thick ${ }^{7} \mathrm{Li}$ and ${ }^{9} \mathrm{Be}$ targets is further investigated here.
Table 1. The reactions under study in the global investigation reviewed in [12-13]. The reactions associated to the neutron production are highlighted with bold fonts.

\begin{tabular}{|c|l|}
\hline $\begin{array}{c}\text { Input } \\
\text { channel }\end{array}$ & \multicolumn{1}{|c|}{ Output channel } \\
\hline & $\rightarrow{ }^{7} \mathrm{Li}+\mathrm{p}$ \\
${ }^{7} \mathrm{Li}+\mathrm{p}$ & $\rightarrow{ }^{7} \mathrm{Li}{ }^{*}+\mathrm{p} \rightarrow{ }^{4} \mathrm{He}+{ }^{3} \mathrm{He}+\mathbf{p}$ \\
& $\rightarrow{ }^{7} \mathbf{B e}+\mathbf{n}$ \\
& $\rightarrow{ }^{4} \mathrm{He}+{ }^{4} \mathrm{He}$ \\
\hline & $\rightarrow{ }^{9} \mathrm{Be}+\mathrm{p}$ \\
& $\rightarrow{ }^{9} \mathbf{B e}^{*}+\mathbf{p} \rightarrow{ }^{4} \mathbf{H e}+{ }^{4} \mathbf{H e}+\mathbf{n}+\mathbf{p}$ \\
& $\rightarrow{ }^{9} \mathbf{B e}^{*}+\mathbf{p} \rightarrow{ }^{8} \mathbf{B e}+\mathbf{p} \rightarrow{ }^{4} \mathbf{H e}+{ }^{4} \mathbf{H e}+\mathbf{n}+\mathbf{p}$ \\
& $\rightarrow{ }^{9} \mathbf{B e}^{*}+\mathbf{p} \rightarrow{ }^{5} \mathbf{H e}+{ }^{4} \mathbf{H e} \rightarrow{ }^{4} \mathbf{H e}+{ }^{4} \mathbf{H e}+\mathbf{n}+\mathbf{p}$ \\
& $\rightarrow{ }^{9} \mathbf{B}+\mathbf{n} \rightarrow{ }^{4} \mathbf{H e}+{ }^{4} \mathrm{He}+\mathbf{p}+\mathbf{n}$ \\
& $\rightarrow{ }^{8} \mathrm{Be}+{ }^{2} \mathrm{H} \rightarrow{ }^{4} \mathrm{He}+{ }^{4} \mathrm{He}+{ }^{2} \mathrm{H}$ \\
& $\rightarrow{ }^{6} \mathrm{Li}+{ }^{4} \mathrm{He}$ \\
& $\rightarrow{ }^{6} \mathrm{Li}+{ }^{4} \mathrm{He}$ \\
\hline
\end{tabular}

\section{Calculation of the neutron rates}

The neutron production for a $1 \mu \mathrm{g} / \mathrm{cm}^{2}$ lithium or beryllium target is presented and discussed in details in Ref. [12]. As it was shown, the ENDF/B-VIII.0 library [24] can be safely used for CANS applications at least in respect with $(p, n)$ reactions. However, one should take into account the breakup for the beryllium target since it accounts for at least $30 \%$ of the total neutron rate. Slowing the protons down to the threshold energy of $(\mathrm{p}, \mathrm{n})$ and breakup reactions and taking into account energy loss algorithms according to Andersen - Ziegler [25], we can calculate the neutron rate for a thick lithium or beryllium target where the proton beam stops inside. The relevant rates are presented in Table 2, while a comparison among themselves is illustrated in Fig. 1. It should be noted that an energy dependence interpolation of the neutron production was assumed paying attention and taking into account the existing resonances.

\footnotetext{
* Corresponding author: vasileios.soukeras@lns.infn.it
} 
Table 2. Neutron rates for ${ }^{7} \mathrm{Li}$ and ${ }^{9} \mathrm{Be}$ thick target. The rates are calculated taking into account $(\mathrm{p}, \mathrm{n})$ cross sections from the ENDF/B-VIII.0 library [24]. For the ${ }^{9} \mathrm{Be}$ target, the neutron production due to breakup was also included, taking into account our recent measurements [13,19-20]. For a smaller energy step see Fig. 1.

\begin{tabular}{|c|c|c|}
\hline $\begin{array}{c}\text { Proton } \\
\text { energy } \\
(\mathrm{MeV})\end{array}$ & $\begin{array}{c}\text { Neutron production } \\
\text { rate with }{ }^{7} \mathrm{Li} \text { target } \\
\left(\mathrm{s}^{-1} \mathrm{~mA}^{-1} \mathrm{sr}^{-1}\right)\end{array}$ & $\begin{array}{c}\text { Neutron production } \\
\text { rate with }{ }^{9} \mathrm{Be} \text { target } \\
\left(\mathrm{s}^{-1} \mathrm{~mA}^{-1} \mathrm{sr}^{-1}\right)\end{array}$ \\
\hline 2.2 & $3.1 \mathrm{E}+10$ & $1.6 \mathrm{E}+08$ \\
\hline 2.5 & $7.9 \mathrm{E}+10$ & $2.1 \mathrm{E}+09$ \\
\hline 3.0 & $1.4 \mathrm{E}+11$ & $1.8 \mathrm{E}+10$ \\
\hline 3.5 & $2.1 \mathrm{E}+11$ & $3.8 \mathrm{E}+10$ \\
\hline 4.0 & $2.8 \mathrm{E}+11$ & $7.0 \mathrm{E}+10$ \\
\hline 4.5 & $3.8 \mathrm{E}+11$ & $1.3 \mathrm{E}+11$ \\
\hline 5.0 & $5.0 \mathrm{E}+11$ & $2.0 \mathrm{E}+11$ \\
\hline 5.2 & $5.5 \mathrm{E}+11$ & $2.3 \mathrm{E}+11$ \\
\hline
\end{tabular}

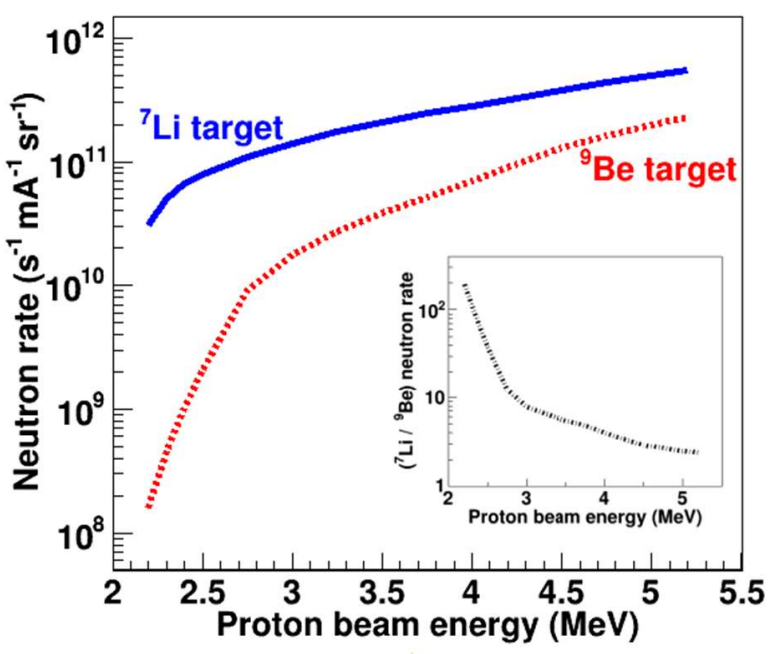

Fig. 1. Neutron rates for ${ }^{7} \mathrm{Li}$ and ${ }^{9} \mathrm{Be}$ thick target as a function of proton beam energy. See text for more details. The energy evolution of the ratio of the neutron rates for the two targets is illustrated in the inset.

\section{Summary}

Promoting the importance of comprehensive studies in the field of low energy proton induced reactions and their connection to societal applications of broad interest, we have presented here neutron rate calculations for thick ${ }^{7} \mathrm{Li}$ and ${ }^{9} \mathrm{Be}$ targets at the proton beam energy range between 2.2 and $5.2 \mathrm{MeV}$. It should be pointed out that breakup reaction is a substantial source of neutrons for the ${ }^{9} \mathrm{Be}$ target however no breakup data are existing in nuclear data libraries.
Finally, the neutron production for a ${ }^{7} \mathrm{Li}$ target is higher however special care should be given at the unnecessary production of radioactive ${ }^{3} \mathrm{H}$ and ${ }^{7} \mathrm{Be}$ in the case of ${ }^{7} \mathrm{Li}$ target [12].

\section{References}

1. I. S. Anderson et al., Phys. Reports 654, 1 (2016).

2. F. Ott, Compact Neutron Sources for Neutron Scattering [Technical Report cea-01873010] CEA Paris Saclay (2018). https://hal-cea.archivesouvertes.fr/cea-01873010/document

3. N. Alamanos, EPJ Web of Conferences, to be published in the present volume (2021).

4. I. Mardor et al., Eur. Phys. J. A 54, 91 (2018).

5. H. Ngoc Tran et al., EPJ Web of Conferences 231, 01007 (2020).

6. http://www.ucans.org/

7. http://www.jcans.net/nuans.html

8. iThemba LABS Long range plan (2018) https://tlabs.ac.za/wpcontent/uploads/pdf/finalLRP may2018c.pdf

9. https://home.infn.it/en/projects-2/progetti-foe/spes

10. https://ceem.indiana.edu/lens/

11. https://exp-astro.de/index.php?id=expFRANZ

12. O. Sgouros et al., Eur. Phys. J. A 57, 125 (2021).

13. A. Pakou et al., Eur. Phys. J. A 57, 25 (2021).

14. A. Pakou et al., Phys. Rev. C 94, 014604 (2016).

15. A. Pakou et al., Phys. Rev. C 95, 044615 (2017).

16. A. Pakou et al., Phys. Rev. C 96, 034615 (2017).

17. N. Keeley et al., Phys. Rev. C 99, 014615 (2019).

18. A. Pakou et al., Phys. Rev. C 101, 024602 (2020).

19. V. Soukeras et al., Phys. Rev. C102, 064622 (2020).

20. A. Pakou et al., Nucl. Phys. A 1008, 122155 (2021).

21. V. Soukeras et al., Phys. Rev. C 91, 057601 (2015).

22. Ch. Betsou et al., Eur. Phys. J. A 51, 86 (2015).

23. V. Soukeras et al., Phys. Rev. C 95, 054614 (2017).

24. Evaluated Nuclear Data File (ENDF) https://www.nndc.bnl.gov/exfor/endf00.jsp

25. H. H. Andersen, J. F. Ziegler, Hydrogen Stopping Powers and Ranges in all elements, vol. 3, Pergamon Press (1977). 